\title{
Correction \\ Correction: Zhang, G., et al. Shadow Detection and Restoration for Hyperspectral Images Based on Nonlinear Spectral Unmixing. Remote Sensing 2020, 12, 3985
}

\author{
Guichen Zhang *(D), Daniele Cerra (D) and Rupert Müller
}

check for updates

Citation: Zhang, G.; Cerra, D.; Müller, R. Correction: Zhang, G., et al Shadow Detection and Restoration for Hyperspectral Images Based on Nonlinear Spectral Unmixing. Remote Sensing 2020, 12, 3985. Remote Sens. 2021, 13, 473. https://doi.org/ $10.3390 /$ rs13030473

Academic Editor: Shaoguang Huang Received: 22 January 2021

Accepted: 25 January 2021

Published: 29 January 2021

Publisher's Note: MDPI stays neutral with regard to jurisdictional claims in published maps and institutional affiliations.

Copyright: (c) 2021 by the authors. Licensee MDPI, Basel, Switzerland. This article is an open access article distributed under the terms and conditions of the Creative Commons Attribution (CC BY) license (https:/ / creativecommons.org/licenses/by/ $4.0 /)$.
Department of Photogrammetry and Remote Sensing, German Aerospace Center (DLR), 88234 Wessling Germany; daniele.cerra@dlr.de (D.C.); rupert.mueller@dlr.de (R.M.)

* Correspondence: guichen.zhang@dlr.de

The authors would like to make the following correction of [1]:

\section{Text Correction}

In the original article, there was a mistake in Equation (8) as published. There should not be the third term $\sum_{i=1}^{p-1} \sum_{j=i+1}^{p} a_{l, i} \cdot a_{l, j} \cdot \boldsymbol{e}_{l, i} \cdot \boldsymbol{e}_{l, j}$, as it is a repetition of the second term in Equation (7). The corrected Equation (8) appears below.

$$
\boldsymbol{x}=\sum_{i=1}^{p} a_{l, i} \cdot \boldsymbol{e}_{l, i}+\sum_{i=1}^{p} a_{s, i} \cdot \boldsymbol{e}_{s, i}
$$

The authors apologize for any inconvenience caused and state that the scientific conclusions are unaffected. The original article has been updated.

In the original article, there was a mistake in Equations (9)-(11) as published. The underline symbol "_" should not be used to represent the subscript, because it is not a unified mathematical expression compared with other equations in the paper.

The corrected Equation (9) appears below.

$$
\boldsymbol{x}_{\text {restore }}=\sum_{i=1}^{p}\left(a_{l, i}+a_{s, i}\right) \cdot \boldsymbol{e}_{l, i}+\sum_{i=1}^{p-1} \sum_{j=i+1}^{p} a_{l, i} \cdot a_{l, j} \cdot \boldsymbol{e}_{l, i} \cdot \boldsymbol{e}_{l, j}
$$

The corrected Equation (10) appears below.

$$
\boldsymbol{x}=\sum_{i=1}^{p} a_{s, i} \cdot e_{s, i}
$$

The corrected Equation (11) appears below.

$$
\boldsymbol{x}=\sum_{i=1}^{p} a_{l, i} \cdot \boldsymbol{e}_{l, i}+\sum_{i=1}^{p-1} \sum_{j=i+1}^{p} a_{l, i} \cdot a_{l, j} \cdot e_{l, i} \cdot e_{l, j}
$$

The authors apologize for any inconvenience caused and state that the scientific conclusions are unaffected. The original article has been updated.

Acknowledgments: The authors would like to thank Paul Scheunders for pointing out the typos.

Conflicts of Interest: The authors declare no conflict of interest.

\section{Reference}

1. Zhang, G.; Cerra, D.; Müller, R. Shadow Detection and Restoration for Hyperspectral Images Based on Nonlinear Spectral Unmixing. Remote Sens. 2020, 12, 3985. [CrossRef] 